\title{
Electronic Textiles Fabricated with Graphene Oxide-Coated Commercial Textiles
}

\author{
Hyun-Seok Jang ${ }^{1,2,3}$, Min Soo Moon ${ }^{1,2,3}$ and Byung Hoon Kim $1,2,3, * \mathbb{C}$ \\ 1 Department of Physics, Incheon National University, Incheon 22012, Korea; slm92jhs@gmail.com (H.-S.J.); \\ mms@inu.ac.kr (M.S.M.) \\ 2 Intelligent Sensor Convergence Research Center, Incheon National University, Incheon 22012, Korea \\ 3 Institute of Basic Science, Incheon National University, Incheon 22012, Korea \\ * Correspondence: kbh37@inu.ac.kr; Tel.: +82-32-835-8229
}

check for

updates

Citation: Jang, H.-S.; Moon, M.-S.; Kim, B.-H. Electronic Textiles

Fabricated with Graphene Oxide-Coated Commercial Textiles. Coatings 2021, 11, 489. https:// doi.org/10.3390/coatings11050489

Academic Editor:

Gonzalo Otero-Irurueta

Received: 26 March 2021

Accepted: 19 April 2021

Published: 22 April 2021

Publisher's Note: MDPI stays neutral with regard to jurisdictional claims in published maps and institutional affiliations.

Copyright: (c) 2021 by the authors. Licensee MDPI, Basel, Switzerland. This article is an open access article distributed under the terms and conditions of the Creative Commons Attribution (CC BY) license (https:// creativecommons.org/licenses/by/ $4.0 /)$.

\begin{abstract}
Demand for wearable and portable electronic devices has increased, raising interest in electronic textiles (e-textiles). E-textiles have been produced using various materials including carbon nanotubes, graphene, and graphene oxide. Among the materials in this minireview, we introduce e-textiles fabricated with graphene oxide (GO) coating, using commercial textiles. GO-coated cotton, nylon, polyester, and silk are reported. The GO-coated commercial textiles were reduced chemically and thermally. The maximum e-textile conductivity of about $10 \mathrm{~S} / \mathrm{cm}$ was achieved in GO-coated silk. We also introduce an e-textile made of uncoated silk. The silk-based e-textiles were obtained using a simple heat treatment with axial tension. The conductivity of the e-textiles was over $100 \mathrm{~S} / \mathrm{cm}$.
\end{abstract}

Keywords: graphene oxide; coating; commercial textiles; electronic textiles

\section{Introduction}

As interest in flexible and portable electronic devices has grown, efforts to develop electronic textiles (e-textiles) have steadily increased [1-8]. Generally, an e-textile is an electrically conducting textile. Studies on e-textiles have frequently employed carbon-based materials because they are highly conductive and lightweight. Among them, electronic yarn and fabric have been obtained from carbon nanotubes (CNT), such as multiwalled carbon nanotube forest synthesized by chemical vapor deposition [1], biscrolling of CNT [2], and core/sheath CNT yarn for wearable supercapacitors [9].

A graphene oxide (GO) has attracted attention as a building block for various applications, including electronic textiles. For e-textiles fabricated with GO itself, GO suspension was put into a pipe, and then the pipe was heated, resulting in various shaped e-textiles [10]. E-textiles with a graphene core-sheath were realized using an electrolyzing method [11]. Graphene fibers and yarns were also fabricated using liquid crystalline dispersions of GO [12,13]. Graphene composite fibers from the reduction of GO fiber have been reported [14], as well as elastic graphene fiber with GO precursors [15], and GO fibers from microfluidic spinning [16]. Hybrid forms of e-textiles using GO/CNT [17-19], GO/CVD graphene [20], and GO/ $\mathrm{MoS}_{2}$ [21] were obtained for energy storage and multifunctional fibers.

These e-textiles, fabricated using only CNT, GO, or their hybrids without commercial (conventional) textiles, exhibit excellent properties and have potential applications in various fields. However, they also have the potential to commercially disrupt the current textile industry. To protect the existing commercial textiles industry, it would be preferable to use both current textiles and the e-textiles fabricated with carbon materials, mentioned above. Many studies have focused on solving this problem. It is well known that the oxygen functional groups (epoxide, hydroxyl, carbonyl, etc.) of GO and reduction with various methods allow GO to have versatile properties: supercapacitors, membranes, sensors, and solar cells [22]. Especially, GO can be coated on lots of materials due to the functional groups. Here we introduce e-textiles obtained from GO-coated commercial textiles. 


\section{Cotton}

\subsection{GO-Coated Cotton}

A sheet resistance of less than $5 \mathrm{k} \Omega$ /sq was achieved by depositing GO onto cotton fabric [23]. The GO was deposited by vacuum filtration, and then the GO-cotton fabric was reduced by the hot press method at $180^{\circ} \mathrm{C}$. The conductivity of the resulting e-textile was $0.9 \mathrm{k} \Omega / \mathrm{sq}$. Shateri-Khalilabad et al. also reported that conducting textiles were obtained from GO-coated cotton textiles [24]. Cotton fabrics were soaked in a $0.05 \%$ aqueous dispersion of GO for $30 \mathrm{~min}$. They were reduced using various reducing agents of $\mathrm{NaBH}_{4}$, $\mathrm{N}_{2} \mathrm{H}_{4}, \mathrm{C}_{6} \mathrm{H}_{8} \mathrm{O}_{6}, \mathrm{Na}_{2} \mathrm{~S}_{2} \mathrm{O}_{4}$, and $\mathrm{NaOH}$. The e-textile reduced by $\mathrm{Na}_{2} \mathrm{~S}_{2} \mathrm{O}_{4}$ showed a surface resistance of $0.374 \mathrm{k} \Omega / \mathrm{cm}$.

Figure 1a shows polypyrrole (PPy)/GO-coated cotton fabric, fabricated by the thermal reduction of $\mathrm{GO}$-coated cotton fabric at $250{ }^{\circ} \mathrm{C}$. After the reduction process, PPy was deposited onto the reduced GO (rGO)-coated fabric by chemical polymerization [25]. The conductivity of the PPy/GO cotton fabric was $1.2 \mathrm{~S} / \mathrm{cm}$ with $336 \mathrm{~F} / \mathrm{g}$ of specific capacitance at a current density of $0.6 \mathrm{~mA} / \mathrm{cm}^{2}$. GO coating on woven cotton was achieved by a screenprinting method, and then GO was reduced electrochemically. The obtained e-textile was adopted for an in-plane supercapacitor (Figure 1b) [26]. Using the screen-printing method, various patterns of rGO electrode can be coated on a textile, which provides the opportunity for fabrication of electronic circuits on the textile. Karim et al. reported that the reduction of $\mathrm{GO}$ with sodium hydrosulfite $\left(\mathrm{Na}_{2} \mathrm{~S}_{2} \mathrm{O}_{4}\right)$, which is widely used for dye reduction in the textile industry, and a simple pad-dry method, were used for e-textile fabrication. Its sheet resistance decreased from $361.82 \mathrm{k} \Omega / \mathrm{sq}$ to $36.94 \mathrm{k} \Omega / \mathrm{sq}$ as the padding pass increased, and it showed potential for the application in a stable activity sensor (Figure 1c) [27]. Figure 1c shows a scalable production method for GO-based textiles. (i) and (iv) represent cleaned cotton fabrics. First, GO coating was performed by putting the cotton fabric into a GO solution in a padding bath with rollers (ii). Second, the GO-coated fabric was dried at $100{ }^{\circ} \mathrm{C}$ for $5 \mathrm{~min}$ (iii). Figure $1 \mathrm{c}(\mathrm{v}, \mathrm{vi})$ show the rGO padded (coated) cotton fabric and its flexibility, respectively. Images obtained by scanning electron microscopy (SEM) of the pristine cotton, $\mathrm{rGO}$-coated cotton fabric, and five times washed e-textile are respectively shown in Figure 1c(vii-ix). The SEM image of the five times washed e-fabric, indicates that the e-fabric is stable for washing.
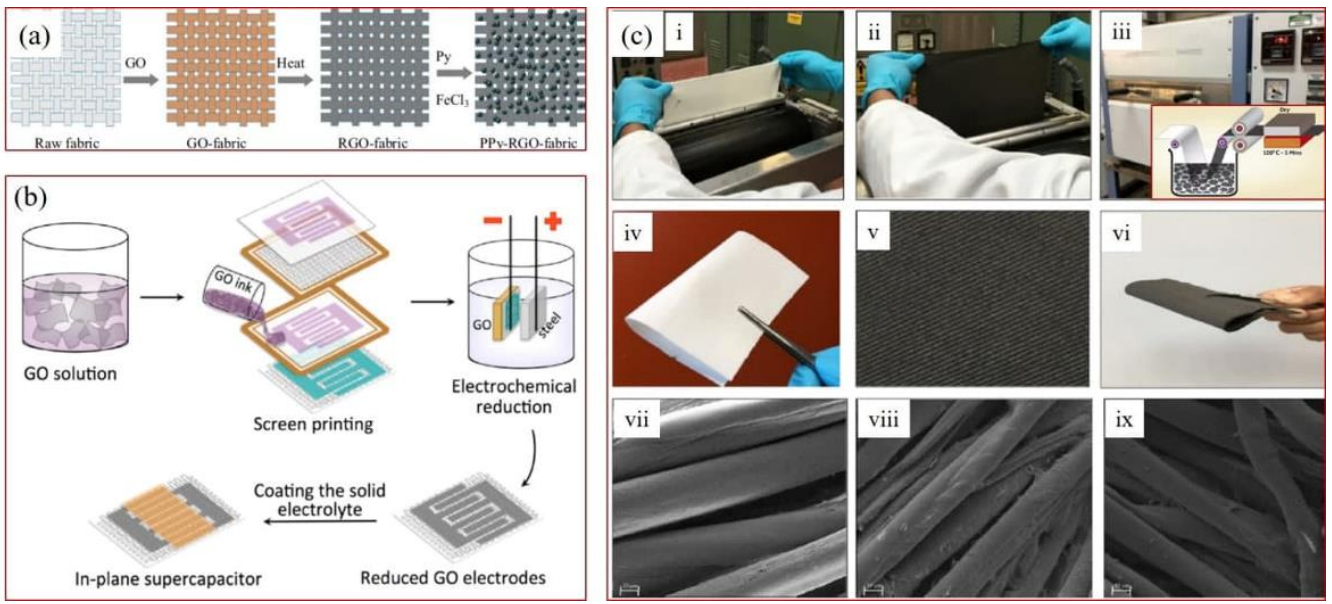

Figure 1. (a) Schematic for fabrication of PPy-rGO-fabric. (b) Schematic of the printed superconductor fabrication process. (c) Scalable production of rGO-coated cotton fabric using padding bath with rollers. Reprinted with permission from References [25-27]. The inset of c(iii) is the scheme of the pad-dry process. Copyright (2015) Elsevier, Copyright (2017) IOP Publishing, and Copyright (2017) American Chemical Society.

Bovine serum albumin (BSA) has been used as an electrostatic glue between GO and commercial textiles. GO-coated cotton fabric using BSA provides a wearable and flexible 
humidity sensor [28]. Figure 2a illustrates the sensor fabrication process. A non-woven cotton fabric (NWCF) was used as a substrate (Figure 2a(i)). A patterned $\mathrm{Cr} / \mathrm{Au}(40 / 160 \mathrm{~nm})$ layer was deposited on the NWCF using a magnetron-sputter (Figure 2a(ii)). Next, the silver leading wires were attached and heated to $120^{\circ} \mathrm{C}$ for $30 \mathrm{~min}$ (Figure 2a(iii)). After coating with BSA (Figure 2a(iv)), the BSA-coated NWCF was soaked in the GO suspension for $2 \mathrm{~h}$ (Figure 2a(v)). Finally, a GO-coated NWCF sensor was obtained (Figure 2a(vi)), which exhibited high flexibility (Figure $2 \mathrm{a}(\mathrm{vii})$ ). Figure $2 \mathrm{~b}(\mathrm{i}, \mathrm{ii})$ shows the resistance response/recovery performances and resistance variations depending on relative humidity levels $(44,55,62,71$, and 91\%). The sensor was very stable during bending (Figure 2b(iii)) and twisting (Figure $2 \mathrm{~b}(\mathrm{iv})$ ). To use BSA as a glue, $\mathrm{pH}$ levels must be controlled. The zeta potential results for $\mathrm{GO}$ were negative values at all $\mathrm{pH}$ levels, but it changed from positive to negative at $\mathrm{pH} 5$ for BSA. This means that the GO is negatively charged, but the positive charges dominate in BSA at $\mathrm{pH}$ levels less than 5. This indicates that the $\mathrm{pH}$ level of the BSA must be less than 5 to attach BSA to the GO surfaces [29].

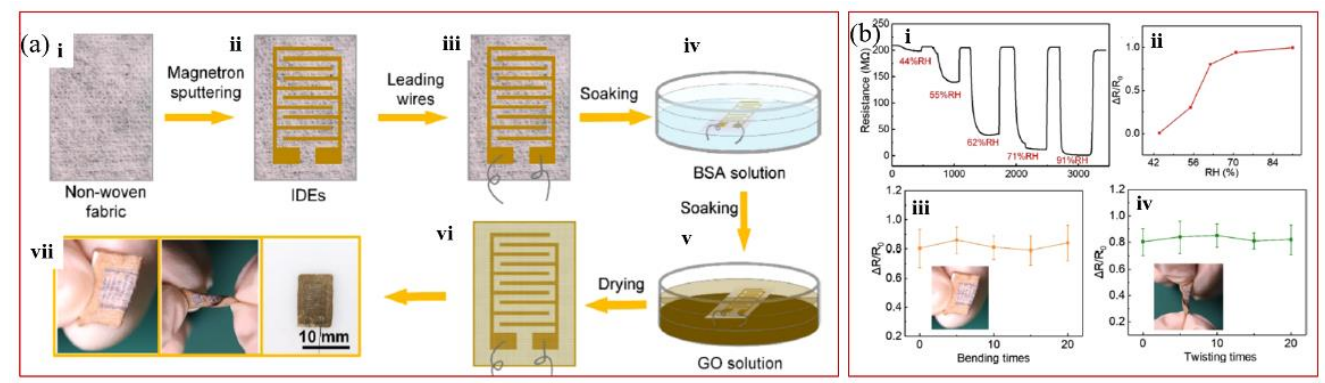

Figure 2. (a) Schematic of the humidity sensor fabrication process. (b) Humidity sensing performance depending on relative humidity (i,ii) and stability for (iii) bending and (iv) twisting. Reprinted with permission from Reference [28]. Copyright (2020) American Chemical Society.

BSA has also been used for coating GO on nylon, polyester, and cotton [29]. rGOcoated mercerized cotton yarns with high stability during bending were reported, showing their potential for a fire/flame monitoring sensor (Figure 3) [30]. The cotton yarns were mercerized by dipping into a $20 \%$ aqueous sodium hydroxide solution for 5 min at various temperatures, up to $100{ }^{\circ} \mathrm{C}$. The mercerized cotton yarns (MCYs) were neutralized by dipping into an acetic acid solution, and then the MCYs were cleaned with DI water. GO coating and infiltration were performed by a simple immersion method. The GO was reduced using $\mathrm{HI}$ acid and sodium acetate at $50{ }^{\circ} \mathrm{C}$ for $30 \mathrm{~min}$ (Figure 3a). A maximum conductivity of $1.0 \mathrm{~S} / \mathrm{cm}$ was exhibited by the rGO-coated MCY, treated by room temperature mercerization. Figure $3 b$ shows the stability of the fire/flame monitoring sensor application using the GO-coated MCYs during bending. rGO-MCY was stitched into a flameproof glove. The real-time recorded sensing data for flat and bent rGO-MCY are presented in Figure $3 \mathrm{~b}(\mathrm{i}, \mathrm{ii})$. The rGO-MCY can continuously monitor the flame. The electrical conductivity of the sensor increased upon exposure to the flame due to the heat from the flame. Figure $3 b(i i i, i v)$ is the sensing data for the flat and bent rGO-MCY, which shows the stability of the fire/flame sensor during bending. The rGO-MCY flame/fire sensor can be useful for firefighters, by implementing the wearable sensor in firefighters' clothing.

The guest materials can enhance the conductivity and endow various properties to e-textiles. Since GO has oxygen functional groups, the other materials are easily decorated to GO-coated textiles. We will briefly introduce the related researches in the next section. 


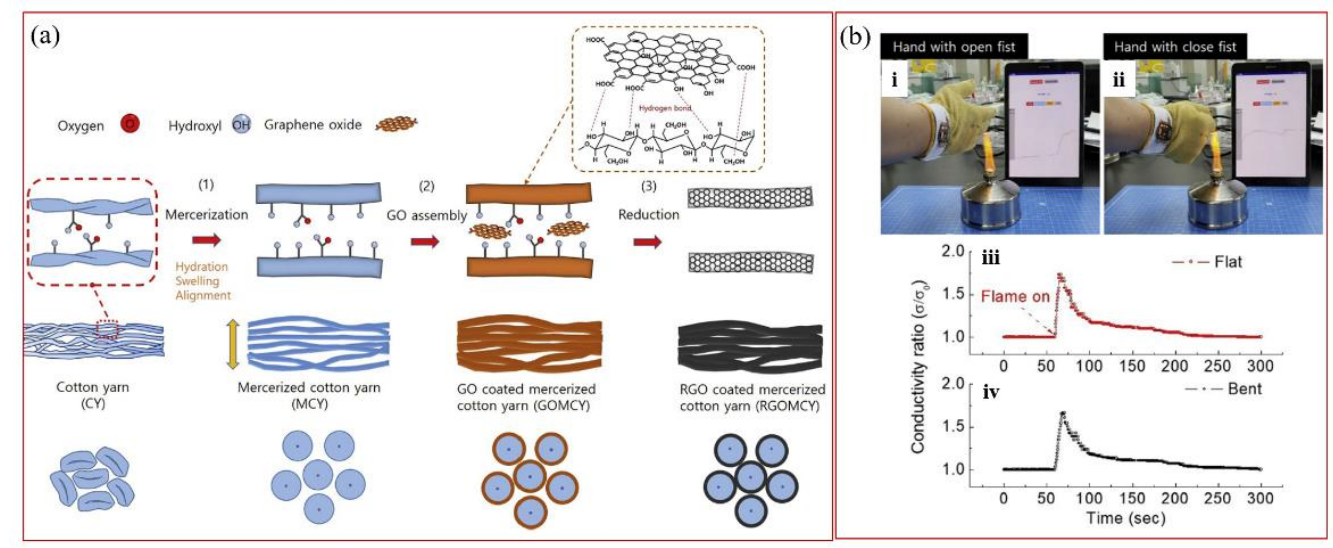

Figure 3. (a) Schematic representation of fabrication process and mechanism of rGO-coated mercerized cotton yarn. (b) Photographs of the smart glove for fire/flame monitoring for the flat and bent yarn. Reprinted with permission from Reference [30]. Copyright (2019) Elsevier.

\subsection{Guest Materials/GO-Coated Cotton}

The reduction of GO using tea carbon dots (TCD) from Assam tea resulted in TCD doped rGO (TCD-rGO). The conducting textile was achieved by pouring the TCD-rGO dispersion on a woven cotton fabric, which subsequently exhibited a conductivity of $6.23 \mathrm{~S} / \mathrm{cm}$ [31]. Graphene and CNT were introduced on a cotton fabric using a dip-coating method with the $\mathrm{TSiPD}^{\bullet+}$ dispersant. In this case, the sheet resistances of the graphene and CNT coated fabric were $29.8 \Omega / \mathrm{sq}$ and $33.2 \Omega / \mathrm{sq}$, respectively [32].

Cotton yarn successively coated by rGO and $\mathrm{ZnO}$ with (3-Aminopropyl)-triethoxysilane, whose role was a glue between $\mathrm{rGO}$ and $\mathrm{ZnO}$, displayed an excellent sensitivity to $\mathrm{NO}_{2}$ gas [33]. Gupta et al. reported that $\mathrm{ZnO}$ was coated on cotton using zinc acetate dihydrate first, and then the GO was coated on the $\mathrm{ZnO}$-coated cotton, which absorbed microwaves [34]. Ghosh et al. showed the electromagnetic interference shielding and antibacterial activity of cotton fabrics with silver nanoparticle-decorated GO [35].

\section{GO-Coated Polyester and Nylon}

GO-coated cotton, polyester (PES) and nylon, have shown conducting behavior using an rGO coating. To coat GO on the surface of PES and nylon, BSA was used as a glue. The GO-coated textiles were then reduced using hydroiodic acid and acetic acid. The conductivity of the e-textiles was about $10 \mathrm{~S} / \mathrm{cm}$, and this level was maintained after bending, twisting, and washing with detergent (Figure 4) [29]. Figure 4a,b displays the SEM images of rGO-coated nylon fiber and knotted rGO-nylon fiber, respectively. The nylon fiber was synthesized by electrospinning. The wrinkles on the surface indicate that rGO has well coated the surface of the nylon fiber. rGO was also coated on commercial PES yarn using BSA (Figure 4c). Wrinkles also appeared on the surface of the rGO-PES yarn (Figure $4 \mathrm{~d}$ ). The rGO-coated nylon fabric was stable after bending (Figure 4e), twisting (Figure 4f), and washing with detergent (Figure 4g).

GO was coated on PES by an immersion and drying method and then chemically reduced using $\mathrm{Na}_{2} \mathrm{~S}_{2} \mathrm{O}_{4}$. As a result, rGO-coated PES was obtained. In addition, Ag nanoparticles were deposited on rGO-coated PES, whose electrical resistivity is $0.35 \mathrm{M} \Omega \mathrm{cm}$, by dipping in an aqueous solution of $\mathrm{AgNO}_{3}$ followed by reduction with $\mathrm{N}_{2} \mathrm{H}_{4} \bullet \mathrm{H}_{2} \mathrm{O}$ [36] $\mathrm{PES} / \mathrm{Ag}$ nanowires/graphene with a core-shell structure was fabricated for wearable triboelectric generators. Ag nanowires were attached to the PES surface by blade-coating and then the GO suspension was coated with the same method. After coating, the GO was reduced by hydrazine-hydrate. The resistance of the resulting textile was $20 \Omega$ /square [37]. rGO-coated PES/cotton electronic fabric was modified with a phosphate flame retardant. It showed $0.546 \mathrm{k} \Omega /$ square and good flame retardancy [38]. 

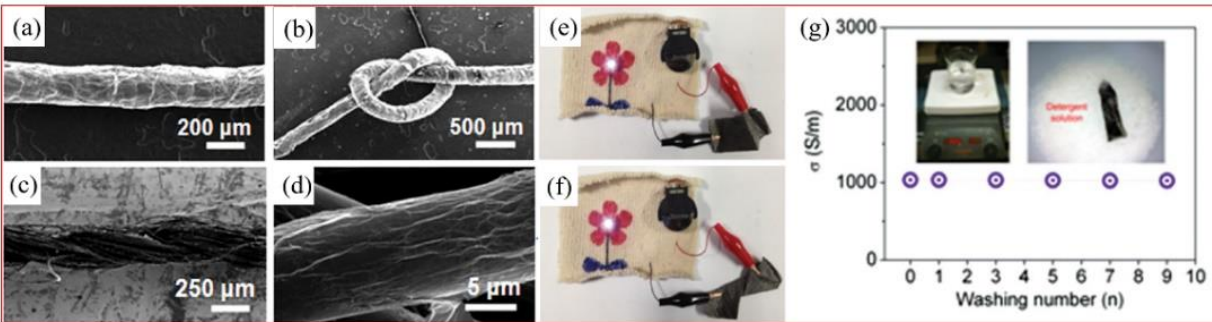

Figure 4. SEM images of (a) rGO-coated nylon fiber, (b) knotted rGO-coated nylon fiber, (c) rGOcoated commercial PES yarn, and (d) wrinkles on the surface of PED yarn. Stability in conducting behavior for (e) bending and (f) twisting. (g) Stability in conductivity for washing with detergent. Reprinted with permission from Reference [29]. Copyright (2013) John Wiley and Sons.

Zhao et al. reported rGO-coated nylon Lycra fabric (rGO-fabric)-based electrodes for supercapacitors [39]. The GO-coated fabric was reduced by a $0.1 \mathrm{M}$ L-ascorbic acid solution at $95^{\circ} \mathrm{C}$. A resistance of $240 \Omega /$ square was achieved with an rGO loading of $2.3 \mathrm{mg} / \mathrm{cm}^{2}$. Interestingly, the initial specific capacitance of the $\mathrm{rGO}$ fabric, $13.5 \mathrm{~F} / \mathrm{g}$, increased up to $114 \mathrm{~F} / \mathrm{g}$ in the PPy-coated rGO fabric. This was interpreted to indicate $\pi-\pi$ stacking interactions between the rGO sheet and the conjugated backbones of the PPy.

A highly sensitive $\mathrm{NO}_{2}$ gas sensor using rGO-coated nylon was realized [40]. First, nylon- 6 nanofibers were deposited on a meshed metal collector (50 meshes) using the electrospinning method (Figure 5a(i-iii)). Second, BSA was functionalized to induce positive charges on the surface of the nylon- 6 nanofibers (Figure 5a(iv)). Third, the resulting mesh was dipped in a low pH-valued GO solution ( $\mathrm{pH} 4.0$ ) (Figure 5a(v)). Finally, chemical reduction was performed using a $\mathrm{HI}$ and acetic acid solution (Figure $5 \mathrm{a}$ (vi)). Figure $5 \mathrm{~b}, \mathrm{c}$ shows optical and SEM images of the e-fabric, respectively. It exhibited high sensitivity and selectivity for $\mathrm{NO}_{2}$ gas (Figure $5 \mathrm{~d}$ ).

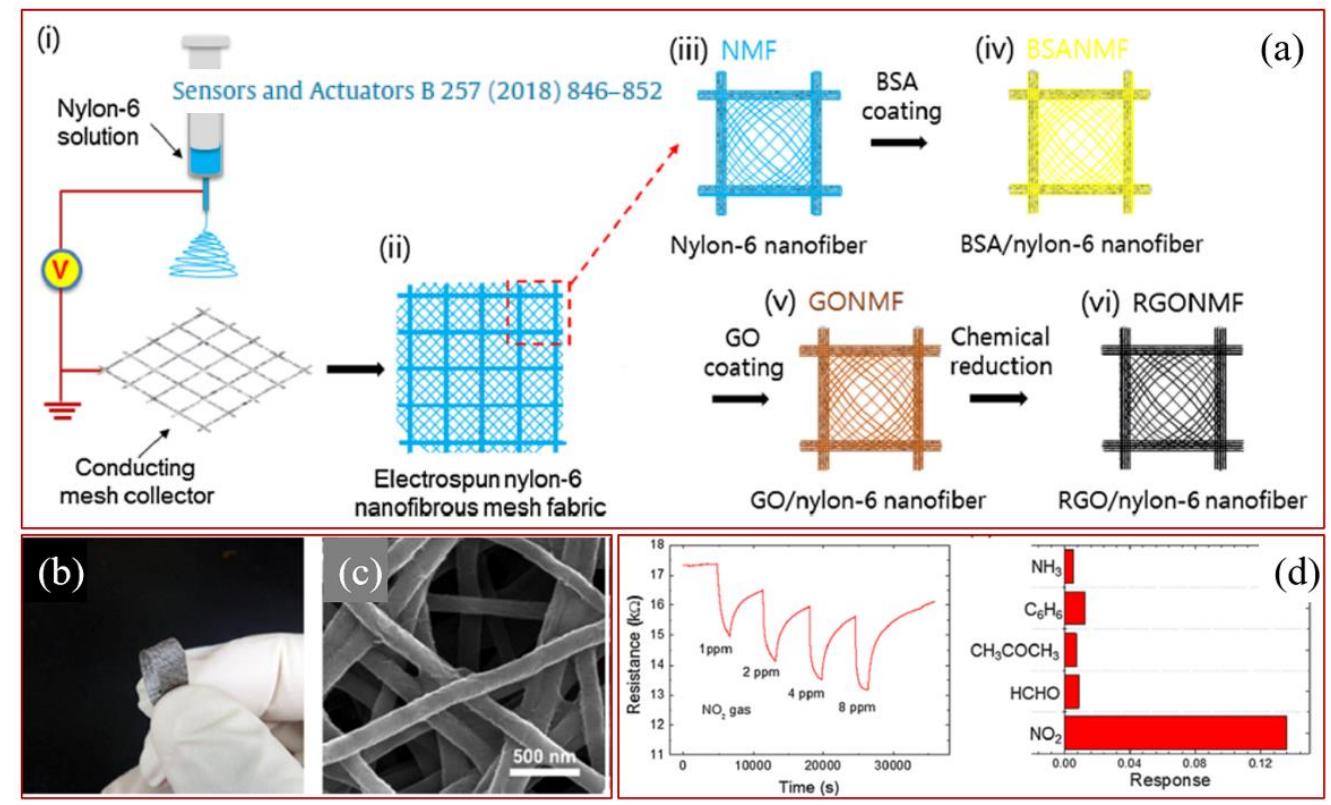

Figure 5. (a) Schematic of the fabrication process of rGO-coated nylon for $\mathrm{NO}_{2}$ gas sensing. (b) Optical image of rGO-coated nylon. (c) SEM image of the e-fabric. (d) Sensitivity and selectivity of the e-fabric for $\mathrm{NO}_{2}$ gas. Reprinted with permission from Reference [40]. Copyright (2018) Elsevier.

\section{E-Textiles Fabricated with Silk}

GO-coated BSA-functionalized silk fabrics were thermally reduced at $200{ }^{\circ} \mathrm{C}$ for $30 \mathrm{~min}$. The resistivity was $23.29 \mathrm{k} \Omega \mathrm{cm}$ using $2 \mathrm{mg} / \mathrm{mL}$ of GO solution, but it decreased to 
$3.28 \mathrm{k} \Omega \mathrm{cm}$ with $5 \mathrm{mg} / \mathrm{mL}$ of GO solution [41]. In fact, the glue-like BSA was not needed to coat GO onto the surface of the silk. Numerous hydrophilic amide groups, including serine, alanine, and glycine in the silk, bonded to the oxygen functional groups in the GO via hydrogen bonding. In addition, crystalline $\beta$-sheets in the silk, provided a hydrophobic interaction with GO [42,43]. Using this property, Jeon et al. reported e-textiles of GO-coated silk and spider web using a simple dipping method without using any glue such as BSA, as shown in Figure 6 [44]. Figure 6a,c is, respectively, SEM images of pristine silk fibroin and spider web, and Figure $6 \mathrm{~b}, \mathrm{~d}$ is the SEM images of the rGO-coated silk fibroin and spider web, respectively. The conducting behavior of both e-textiles is shown in Figure 6e (rGO-silk yarn) and Figure $6 \mathrm{f}$ (rGO-spider web). The conductivities were approximately $4.76 \times 10^{-1} \mathrm{~S} / \mathrm{cm}$ for the rGO-coated silk yarn and $5.95 \times 10^{-4} \mathrm{~S} / \mathrm{cm}$ for the rGO-coated spider web. In the rGO-coated silk fabric, the conductivity reached up to $10 \mathrm{~S} / \mathrm{cm}$. They also fabricated a wearable $\mathrm{NO}_{2}$ gas sensor using $\mathrm{GO}$-coated silk fabric [45]. A simple method of dipping the silk fabric in a GO solution $(1.0 \mathrm{mg} / \mathrm{mL})$, was used to prepare the gas sensor. The GO-coated silk was thermally treated at 400,500 , and $600{ }^{\circ} \mathrm{C}$. A gas sensing response of $24 \%$ was attained with the GO-coated silk reduced at $400{ }^{\circ} \mathrm{C}$, when the sensor was exposed to $10 \mathrm{ppm} \mathrm{NO}_{2}$ gas. This performance was attributed to the large surface area and optimum pore-size.
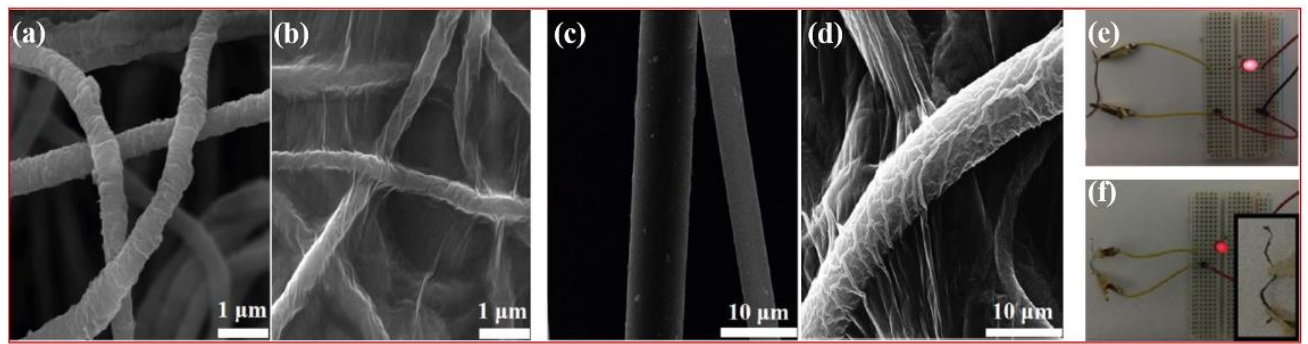

Figure 6. SEM images of (a) silk fibroin, (b) rGO-coated silk fibroin, (c) spider web, and (d) rGOcoated spider web. The electrical conductor of (e) rGO-silk yarn and (f) rGO-spider web. Reprinted with permission from Reference [44]. Copyright (2017) John Wiley and Sons.

The electrical conducting property of silk has also been enhanced without GO coating. The basic building blocks of silk can be transformed into a hexagonal carbon structure by heat treatment. The conductivity of the heat-treated silk fibroins increased as the heat treatment temperature (HTT) increased $\left(4.48 \times 10^{2} \mathrm{~S} / \mathrm{cm}\right.$ for $800^{\circ} \mathrm{C} \mathrm{HTT}$ and $4.37 \times 10^{5} \mathrm{~S} / \mathrm{cm}$ for $2800{ }^{\circ} \mathrm{C} \mathrm{HTT}$ ) [46]. Using this property, flexible and wearable e-textiles having high conductivity and high thermal durability, can be fabricated with silk (Figure 7a) [47]. A long-range ordered carbon structure was obtained with commercial silk after thermal treatment up to $1400{ }^{\circ} \mathrm{C}$ with axial stretching. The conductivities of the silk fibroin and commercial silk yarn treated at $1000{ }^{\circ} \mathrm{C}$ were $1201 \mathrm{~S} / \mathrm{cm}$ and $150 \mathrm{~S} / \mathrm{cm}$, respectively. The conductivity increased as HTT and the axial tensile stress were increased (Figure $7 \mathrm{~b}$ ). These e-textiles, fabricated at high temperatures, also showed high thermal durability (Figure 7c,d). This high thermal durability allows depositing various materials such as $\mathrm{ZnO}, \mathrm{MoSe}_{2}$, and $\mathrm{NbN}$ using standard sputtering and evaporation techniques. This can endow semiconducting and superconducting behavior to the e-fabric. 

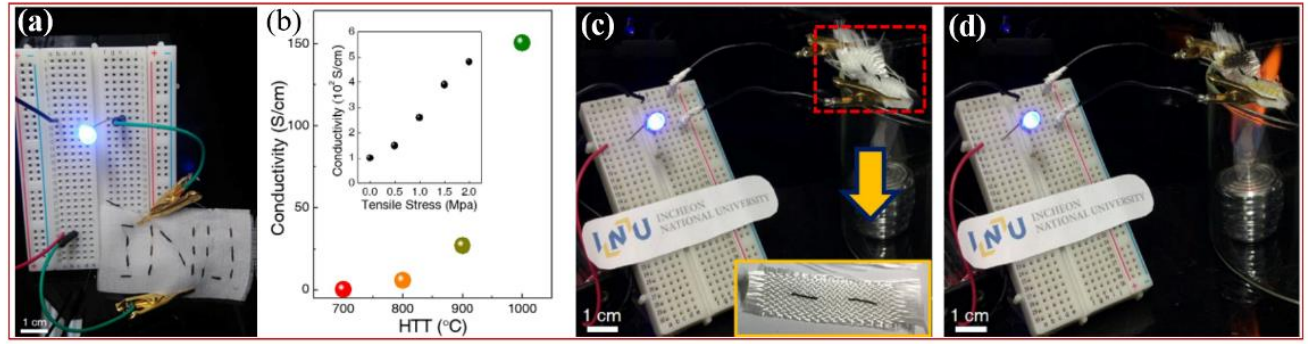

Figure 7. (a) Conducting behavior of commercial silk yarn. (b) HTT-dependent conductivity. (c,d) Thermal durability of the e-textile. Reprinted with permission from Reference [47]. Copyright (2018) Elsevier.

\section{Outlook}

We have introduced rGO-coated e-textiles fabricated with commercial textiles, cotton, polyester, nylon, and silk. GO coating onto the textiles was achieved by vacuum filtration, simple dipping, screen-printing, spraying, and blade-coating. The electrical conductivity of the e-textiles is generated from the reduction of GO by heat treatment (HT), chemicals, or electrochemical processes. The maximum conductivity order of $101 \mathrm{~S} / \mathrm{cm}$ was reported with the e-textiles reduced by HT, HI and acetic acids (Table 1).

Table 1. Characteristics of rGO-coated e-textiles. The different conductivity came from the reduction methods, reduction temperature, and heating rate $\left({ }^{\circ} \mathrm{C} / \mathrm{min}\right)$.

\begin{tabular}{|c|c|c|c|c|c|}
\hline $\begin{array}{l}\text { Commercial } \\
\text { Textiles }\end{array}$ & Coating Method & Reduction Method & Conductivity & $\begin{array}{c}\text { Specific } \\
\text { Capacitance }\end{array}$ & Reference \\
\hline \multirow{9}{*}{ Cotton } & Vacuum filtration & HT at $453 \mathrm{~K}$ & $1.1 \times 10^{-3} \mathrm{~S} / \mathrm{sq}$ & - & [23] \\
\hline & Soak-coating & $\mathrm{Na}_{2} \mathrm{~S}_{2} \mathrm{O}_{4}$ & $2.7 \times 10^{-3} \mathrm{~S} / \mathrm{cm}$ & - & [24] \\
\hline & Dip-coating & $\mathrm{HT}$ at $523 \mathrm{~K}$ & $1.2 \mathrm{~S} / \mathrm{cm}$ & $336 \mathrm{~F} / \mathrm{g}$ & [25] \\
\hline & Screen printing & Electrochemical & $9.1 \times 10^{-6} \mathrm{~S} / \mathrm{sq}$ & $257 \mathrm{~F} / \mathrm{g}$ & [26] \\
\hline & Padding/drying & $\mathrm{Na}_{2} \mathrm{~S}_{2} \mathrm{O}_{4}$ & $2.7 \times 10^{-5} \mathrm{~S} / \mathrm{sq}$ & - & [27] \\
\hline & Dip-coating & HI acid and sodium acetate & $1.0 \mathrm{~S} / \mathrm{cm}$ & - & {$[30]$} \\
\hline & Dip-coating & Tea carbon dots & $6.2 \mathrm{~S} / \mathrm{cm}$ & - & [31] \\
\hline & Spray-coating & $\mathrm{HT}$ at $873 \mathrm{~K}$ & $15.8 \mathrm{~S} / \mathrm{cm}$ & - & {$[32]$} \\
\hline & Dip-coating & Hydrazine hydrate & $1.7 \mathrm{~S} / \mathrm{cm}$ & - & [33] \\
\hline \multirow{3}{*}{ Polyester } & Dip-coating & HI acid and acetic acid & $10 \mathrm{~S} / \mathrm{cm}$ & - & [29] \\
\hline & Dip-coating & $\mathrm{Na}_{2} \mathrm{~S}_{2} \mathrm{O}_{4}$ & $2.9 \times 10^{-6} \mathrm{~S} / \mathrm{cm}$ & - & [36] \\
\hline & Blade-coating & Hydrazine hydrate & $0.05 \mathrm{~S} / \mathrm{sq}$ & - & {$[37]$} \\
\hline \multirow{2}{*}{ Nylon } & Dip-coating & HI acid and acetic acid & $10 \mathrm{~S} / \mathrm{cm}$ & - & [29] \\
\hline & Dip-coating & L-ascorbic acid & $4.2 \times 10^{-3} \mathrm{~S} / \mathrm{sq}$ & $114 \mathrm{~F} / \mathrm{g}$ & [39] \\
\hline \multirow{3}{*}{ Silk } & Dip-coating & HT at $473 \mathrm{~K}$ & $3.0 \times 10^{-4} \mathrm{~S} / \mathrm{cm}$ & - & [41] \\
\hline & Dip-coating & $\mathrm{HT}$ at $523 \mathrm{~K}$ & $10 \mathrm{~S} / \mathrm{cm}$ & - & [44] \\
\hline & Dip-coating & $\mathrm{HT}$ at $1173 \mathrm{~K}$ & $100 \mathrm{~S} / \mathrm{cm}$ & - & Unpublished \\
\hline
\end{tabular}

An e-textile can be used for various applications such as gas sensors, supercapacitors, flame/fire sensors, shielding of electromagnetic waves as mentioned before, as well as human health, medicine [4-6], and biology [7]. In this light, GO-coated e-textiles can break the barriers in the way of e-textiles gaining more applications, because lots of materials for the various applications can be attached to GO. However, the most critical applications of e-textiles may be flexible and wearable electronics. To reach this goal, essentially, the e-textiles having high conductivity is inevitable. Although we obtained the conductivity of $100 \mathrm{~S} / \mathrm{cm}$ in GO-coated silk (unpublished), the conductivity of the rGO-coated textiles is too low, as shown in Table 1. To use rGO-coated e-textiles in flexible and wearable electronics, methods for increasing conductivity need to be found. For example the new reduction method, and metal nanoparticle-dipping and nanowelding between the nanoparticles, like Au nanowelding in $\mathrm{SiO}_{2}$ [48]. 


\section{Conclusions}

We have reviewed a number of different rGO-coated e-textiles. rGO-coating has been applied to commercial textiles including cotton, nylon, polyester, and silk. This GO coating was achieved by simple dipping, or using BSA as a glue between the commercial textiles and GO. The reduction of the coated GO was performed using chemicals (HI, acetic acid and $\mathrm{Na}_{2} \mathrm{~S}_{2} \mathrm{O}_{4}$ ), microwaves, or heat treatment at various temperatures. The resulting etextiles exhibited conductivities from $10^{-5}$ to $10 \mathrm{~S} / \mathrm{cm}$ depending on the reduction methods and temperatures. The commercial silk-based textiles without GO coating showed the highest conductivity, $100 \mathrm{~S} / \mathrm{cm}$.

These e-textiles have been employed for supercapacitors, $\mathrm{NO}_{2}$ gas sensors, fire/flame retardants, and electromagnetic wave absorption and shielding with guest materials. Such commercial textile-based e-textiles will provide a workable solution for the future textile industry.

Author Contributions: Conceptualization, B.H.K.; methodology, B.H.K. and H.-S.J.: data collection, B.H.K., H.-S.J., M.S.M.; writing, B.H.K., H.-S.J., M.S.M.; review and editing, B.H.K. and H.-S.J.; supervision, B.H.K. and H.-S.J. All authors have read and agreed to the published version of the manuscript.

Funding: This work was supported by the Basic Science Research Program through the National Research Foundation of Korea (NRF) funded by the Ministry of Education (NRF-2020R1A2C4001513).

Institutional Review Board Statement: Not applicable.

Informed Consent Statement: Not applicable.

Conflicts of Interest: The authors declare no conflict of interest.

\section{References}

1. Zhang, M.; Atkinson, K.R.; Baughman, R.H. Multifunctional carbon nanotube yarns by downsizing an ancient technology. Science 2004, 306, 1358-1361. [CrossRef]

2. $\quad$ Lima, M.D.; Fang, S.; Lepró, X.; Lewis, C.; Ovalle-Robles, R.; Carretero-González, J.; Castillo-Martínez, E.; Kozlov, M.E.; Oh, J.; Rawat, N.; et al. Biscrolling nanotube sheets and functional guests into yarns. Science 2011, 331, 51-55. [CrossRef] [PubMed]

3. Wen, Z.; Yeh, M.H.; Guo, H.; Wang, J.; Zi, Y.; Xu, W.; Deng, J.; Zhu, L.; Wang, X.; Hu, C.; et al. Self-powered textile for Wearable electronics by hybridizing fiber-shaped nanogenerators, solar cells, and supercapacitors. Sci. Adv. 2016, 2. [CrossRef]

4. Hsu, P.; Liu, C.; Song, A.Y.; Zhang, Z.; Peng, Y.; Xie, J.; Liu, K.; Wu, C.; Catrysse, P.B.; Cai, L.; et al. A dual-mode textile for human body radiative heating and cooling. Sci. Adv. 2017, 3. [CrossRef] [PubMed]

5. Gambhir, S.S.; Ge, T.J.; Vermesh, O.; Spitler, R. Toward achieving precision health. Sci. Transl. Med. 2018, 10, 1-6. [CrossRef]

6. Fan, W.; He, Q.; Meng, K.; Tan, X.; Zhou, Z.; Zhang, G.; Yang, J.; Wang, Z.L. Machine-knitted washable sensor array textile for precise epidermal physiological signal monitoring. Sci. Adv. 2020, 6, 1-11. [CrossRef] [PubMed]

7. Ham, S.; Kang, M.; Jang, S.; Jang, J.; Choi, S.; Kim, T.W.; Wang, G. One-dimensional organic artificial multi-synapses enabling electronic textile neural network for wearable neuromorphic applications. Sci. Adv. 2020, 6, 1-10. [CrossRef]

8. Yan, J.; Zhang, Y.; Zhao, Y.; Song, J.; Xia, S.; Liu, S.; Yu, J.; Ding, B. Transformation of oxide ceramic textiles from insulation to conduction at room temperature. Sci. Adv. 2020, 6, 1-9. [CrossRef] [PubMed]

9. Zhang, D.; Miao, M.; Niu, H.; Wei, Z. Core-spun carbon nanotube yarn supercapacitors for wearable electronic textiles. ACS Nano 2014, 8, 4571-4579. [CrossRef]

10. Dong, Z.; Jiang, C.; Cheng, H.; Zhao, Y.; Shi, G.; Jiang, L.; Qu, L. Facile fabrication of light, flexible and multifunctional graphene fibers. Adv. Mater. 2012, 24, 1856-1861. [CrossRef] [PubMed]

11. Meng, Y.; Zhao, Y.; Hu, C.; Cheng, H.; Hu, Y.; Zhang, Z.; Shi, G.; Qu, L. All-graphene core-sheath microfibers for all-solid-state, stretchable fibriform supercapacitors and wearable electronic textiles. Adv. Mater. 2013, 25, 2326-2331. [CrossRef]

12. Jalili, R.; Aboutalebi, S.H.; Esrafilzadeh, D.; Shepherd, R.L.; Chen, J.; Aminorroaya-Yamini, S.; Konstantinov, K.; Minett, A.I.; Razal, J.M.; Wallace, G.G. Scalable one-step wet-spinning of graphene fibers and yarns from liquid crystalline dispersions of graphene oxide: Towards multifunctional textiles. Adv. Funct. Mater. 2013, 23, 5345-5354. [CrossRef]

13. Aboutalebi, S.H.; Jalili, R.; Esrafilzadeh, D.; Salari, M.; Gholamvand, Z.; Aminorroaya Yamini, S.; Konstantinov, K.; Shepherd, R.L.; Chen, J.; Moulton, S.E.; et al. High-performance multifunctional Graphene yarns: Toward wearable all-carbon energy storage textiles. ACS Nano 2014, 8, 2456-2466. [CrossRef]

14. Yang, Z.; Sun, H.; Chen, T.; Qiu, L.; Luo, Y.; Peng, H. Photovoltaic Wire Derived from a Graphene Composite Fiber Achieving an 8.45\% Energy Conversion Efficiency. Angew. Chem. 2013, 125, 7693-7696. [CrossRef]

15. Huang, G.; Hou, C.; Shao, Y.; Wang, H.; Zhang, Q.; Li, Y.; Zhu, M. Highly strong and elastic graphene fibres prepared from universal graphene oxide precursors. Sci. Rep. 2014, 4, 1-6. [CrossRef] [PubMed] 
16. Hu, X.; Tian, M.; Pan, N.; Sun, B.; Li, Z.; Ma, Y.; Zhang, X.; Zhu, S.; Chen, Z.; Qu, L. Structure-tunable graphene oxide fibers via microfluidic spinning route for multifunctional textile. Carbon N. Y. 2019, 152, 106-113. [CrossRef]

17. Wang, S.; Liu, N.; Su, J.; Li, L.; Long, F.; Zou, Z.; Jiang, X.; Gao, Y. Highly Stretchable and Self-Healable Supercapacitor with Reduced Graphene Oxide Based Fiber Springs. ACS Nano 2017, 11, 2066-2074. [CrossRef]

18. Choi, C.; Park, J.W.; Kim, K.J.; Lee, D.W.; De Andrade, M.J.; Kim, S.H.; Gambhir, S.; Spinks, G.M.; Baughman, R.H.; Kim, S.J. Weavable asymmetric carbon nanotube yarn supercapacitor for electronic textiles. RSC Adv. 2018, 8, 13112-13120. [CrossRef]

19. Ma, W.; Li, M.; Zhou, X.; Li, J.; Dong, Y.; Zhu, M. Three-Dimensional Porous Carbon Nanotubes/Reduced Graphene Oxide Fiber from Rapid Phase Separation for a High-Rate All-Solid-State Supercapacitor. ACS Appl. Mater. Interfaces 2019, 11, 9283-9290. [CrossRef]

20. Choi, Y.S.; Yeo, C.S.; Kim, S.J.; Lee, J.Y.; Kim, Y.; Cho, K.R.; Ju, S.; Hong, B.H.; Park, S.Y. Multifunctional reduced graphene oxide-CVD graphene core-shell fibers. Nanoscale 2019, 11, 12637-12642. [CrossRef] [PubMed]

21. Li, J.; Shao, Y.; Jiang, P.; Zhang, Q.; Hou, C.; Li, Y.; Wang, H. 1T-Molybdenum disulfide/reduced graphene oxide hybrid fibers as high strength fibrous electrodes for wearable energy storage. J. Mater. Chem. A 2019, 7, 3143-3149. [CrossRef]

22. Tarcan, R.; Todor-Boer, O.; Petrovai, I.; Leordean, C.; Astilean, S.; Botiz, I. Reduced graphene oxide today. J. Mater. Chem. A 2020, 8, 1198-1224. [CrossRef]

23. Ren, J.; Wang, C.; Zhang, X.; Carey, T.; Chen, K.; Yin, Y.; Torrisi, F. Environmentally-friendly conductive cotton fabric as flexible strain sensor based on hot press reduced graphene oxide. Carbon N. Y. 2017, 111, 622-630. [CrossRef]

24. Shateri-Khalilabad, M.; Yazdanshenas, M.E. Fabricating electroconductive cotton textiles using graphene. Carbohydr. Polym. 2013, 96, 190-195. [CrossRef]

25. Xu, J.; Wang, D.; Yuan, Y.; Wei, W.; Duan, L.; Wang, L.; Bao, H.; Xu, W. Polypyrrole/reduced graphene oxide coated fabric electrodes for supercapacitor application. Org. Electron. 2015, 24, 153-159. [CrossRef]

26. Abdelkader, A.M.; Karim, N.; Vallés, C.; Afroj, S.; Novoselov, K.S.; Yeates, S.G. Ultraflexible and robust graphene supercapacitors printed on textiles for wearable electronics applications. 2D Mater. 2017, 4. [CrossRef]

27. Karim, N.; Afroj, S.; Tan, S.; He, P.; Fernando, A.; Carr, C.; Novoselov, K.S. Scalable Production of Graphene-Based Wearable E-Textiles. ACS Nano 2017, 11, 12266-12275. [CrossRef] [PubMed]

28. Wang, Y.; Zhang, L.; Zhang, Z.; Sun, P.; Chen, H. High-Sensitivity Wearable and Flexible Humidity Sensor Based on Graphene Oxide/Non-Woven Fabric for Respiration Monitoring. Langmuir 2020, 36, 9443-9448. [CrossRef]

29. Yun, Y.J.; Hong, W.G.; Kim, W.J.; Jun, Y.; Kim, B.H. A novel method for applying reduced graphene oxide directly to electronic textiles from yarns to fabrics. Adv. Mater. 2013, 25, 5701-5705. [CrossRef] [PubMed]

30. Yun, Y.J.; Lee, H.J.; Son, T.H.; Son, H.; Jun, Y. Mercerization to enhance flexibility and electromechanical stability of reduced graphene oxide cotton yarns. Compos. Sci. Technol. 2019, 184, 107845. [CrossRef]

31. Konwar, A.; Baruah, U.; Deka, M.J.; Hussain, A.A.; Haque, S.R.; Pal, A.R.; Chowdhury, D. Tea-Carbon Dots-Reduced Graphene Oxide: An Efficient Conducting Coating Material for Fabrication of an E-Textile. ACS Sustain. Chem. Eng. 2017, 5, 11645-11651. [CrossRef]

32. Cui, J.; Zhou, S. Highly conductive and ultra-durable electronic textiles via covalent immobilization of carbon nanomaterials on cotton fabric. J. Mater. Chem. C 2018, 6, 12273-12282. [CrossRef]

33. Li, W.; Chen, R.; Qi, W.; Cai, L.; Sun, Y.; Sun, M.; Li, C.; Yang, X.; Xiang, L.; Xie, D.; et al. Reduced Graphene Oxide/Mesoporous ZnO NSs Hybrid Fibers for Flexible, Stretchable, Twisted, and Wearable $\mathrm{NO}_{2}$ E-Textile Gas Sensor. ACS Sens. 2019, 4, $2809-2818$. [CrossRef]

34. Gupta, S.; Chang, C.; Anbalagan, A.K.; Lee, C.H.; Tai, N.H. Reduced graphene oxide/zinc oxide coated wearable electrically conductive cotton textile for high microwave absorption. Compos. Sci. Technol. 2020, 188, 107994. [CrossRef]

35. Ghosh, S.; Ganguly, S.; Das, P.; Das, T.K.; Bose, M.; Singha, N.K.; Das, A.K.; Das, N.C. Fabrication of Reduced Graphene Oxide/Silver Nanoparticles Decorated Conductive Cotton Fabric for High Performing Electromagnetic Interference Shielding and Antibacterial Application. Fibers Polym. 2019, 20, 1161-1171. [CrossRef]

36. Ouadil, B.; Cherkaoui, O.; Safi, M.; Zahouily, M. Surface modification of knit polyester fabric for mechanical, electrical and UV protection properties by coating with graphene oxide, graphene and graphene/silver nanocomposites. Appl. Surf. Sci. 2017, 414, 292-302. [CrossRef]

37. Wu, C.; Kim, T.W.; Li, F.; Guo, T. Wearable Electricity Generators Fabricated Utilizing Transparent Electronic Textiles Based on Polyester/Ag Nanowires/Graphene Core-Shell Nanocomposites. ACS Nano 2016, 10, 6449-6457. [CrossRef] [PubMed]

38. Zhao, Y.; Wang, J.; Li, Z.; Zhang, X.; Tian, M.; Zhang, X.; Liu, X.; Qu, L.; Zhu, S. Washable, durable and flame retardant conductive textiles based on reduced graphene oxide modification. Cellulose 2020, 27, 1763-1771. [CrossRef]

39. Zhao, C.; Shu, K.; Wang, C.; Gambhir, S.; Wallace, G.G. Reduced graphene oxide and polypyrrole/reduced graphene oxide composite coated stretchable fabric electrodes for supercapacitor application. Electrochim. Acta 2015, 172, 12-19. [CrossRef]

40. Park, H.J.; Kim, W.J.; Lee, H.K.; Lee, D.S.; Shin, J.H.; Jun, Y.; Yun, Y.J. Highly flexible, mechanically stable, and sensitive NO2 gas sensors based on reduced graphene oxide nanofibrous mesh fabric for flexible electronics. Sens. Actuators B Chem. 2018, 257, 846-852. [CrossRef]

41. Zulan, L.; Zhi, L.; Lan, C.; Sihao, C.; Dayang, W.; Fangyin, D. Reduced Graphene Oxide Coated Silk Fabrics with Conductive Property for Wearable Electronic Textiles Application. Adv. Electron. Mater. 2019, 5, 1-9. [CrossRef] 
42. Hu, K.; Gupta, M.K.; Kulkarni, D.D.; Tsukruk, V.V. Ultra-robust graphene oxide-silk fibroin nanocomposite membranes. Adv. Mater. 2013, 25, 2301-2307. [CrossRef]

43. Huang, L.; Li, C.; Yuan, W.; Shi, G. Strong composite films with layered structures prepared by casting silk fibroin-graphene oxide hydrogels. Nanoscale 2013, 5, 3780-3786. [CrossRef]

44. Jeon, J.W.; Cho, S.Y.; Jeong, Y.J.; Shin, D.S.; Kim, N.R.; Yun, Y.S.; Kim, H.T.; Choi, S.B.; Hong, W.G.; Kim, H.J.; et al. PyroproteinBased Electronic Textiles with High Stability. Adv. Mater. 2017, 29, 1-6. [CrossRef]

45. Jung, W.T.; Jeon, J.W.; Jang, H.S.; Kim, D.Y.; Lee, H.K.; Kim, B.H. Commercial silk-based electronic textiles for $\mathrm{NO}_{2}$ sensing. Sens. Actuators B Chem. 2020, 307, 127596. [CrossRef]

46. Cho, S.Y.; Yun, Y.S.; Jang, D.; Jeon, J.W.; Kim, B.H.; Lee, S.; Jin, H.J. Ultra strong pyroprotein fibres with long-range ordering. Nat. Commun. 2017, 8, 1-7. [CrossRef]

47. Jeon, J.W.; Oh, J.Y.; Cho, S.Y.; Lee, S.; Jang, H.S.; Jung, W.T.; Kim, J.G.; Kim, H.; Kim, H.J.; Kim, S.Y.; et al. Pyroprotein-based electronic textiles with high thermal durability. Mater. Today 2018, 21, 944-950. [CrossRef]

48. Son, M.; Jeong, S.; Jang, D.-J. Laser-induced nanowelding of linearly assembled and silica-coated gold nanorods to fabricate $\mathrm{Au} @ \mathrm{SiO}_{2}$ core-shell nanowires. J. Phys. Chem. C 2014, 118, 5961-5967. [CrossRef] 